\title{
The Perspectives of Students and Teachers in the English Department in the College of Basic Education on the Student Evaluation of Teachers
}

\author{
Hanan A. Taqi ${ }^{1}$, Nowreyah A. Al-Nouh ${ }^{1}$, Abdulmuhsin A. Dashti ${ }^{1} \&$ Khaled M. Shuqair ${ }^{1}$ \\ ${ }^{1}$ English Language Department, CBE, Ardhyia, Kuwait \\ Corresponding: Hanan Taqi, The English Department, College of basic Education, Kuwait. Tel: 965-96-088-100. \\ E-mail: hanan.taqi@gmail.com
}

Received: September 25, 2014

Accepted: October 23, $2014 \quad$ Online Published: November 10, 2014

doi:10.5539/jel.v3n4p71

URL: http://dx.doi.org/10.5539/jel.v3n4p71

\begin{abstract}
In the context of students' evaluation of teachers in higher education, this paper examines the perspectives of students and faculty members in the English Department in the college of Basic education (CBE) in the State of Kuwait. The study is based on a survey that covered 320 students and 19 members of staff in the English department. The study was based on a 20 statements questionnaire; in addition to two open ended questions. The data collected was analyzed through the use of SPSS, and the open-ended questions were analyzed manually. The findings reveal a general agreement on several academic and structural issues concerning the evaluation form. Both students and teachers expressed their views in detail concerning the evaluation process. Finally, a number of recommendations based on the students' and teachers' perspectives will be given in order to make the students' evaluation of teachers more valuable and beneficial.
\end{abstract}

Keywords: English department, higher education, SET, evaluation form, student and teacher perspective, CBE, college

\section{Introduction}

Student evaluation of teaching (SET) started in most colleges and universities in North America in the late 1960's or early 1970's (Canelos, 1985; Murray, 2005). The beginnings of SET were at Harvard University and the University of Washington in the 1920's, introduced by psychologist E.T. Guthrie. In the new millennium, the application of SET has been acknowledged worldwide.

Previous research suggests that students' evaluations encourage the recognition and appreciation of excellence in teaching (Carr \& Hagel, 2008). There are two types of SET: Formative, which uses students' feedback to update the quality of instructors' teaching, and summative, which uses the information to sum up instructors' performance to aid in their promotion (Berk, 2005). The present study, however, is interested in the second type of SET as it is the one currently used in the College of Basic Education.

The present study was conducted in the College of Basic Education in Kuwait. The graduates of this college majorly become teachers in primary schools. The college offers a range of courses, which are offered according to the students' major. The participants in this study were teachers and students from the English Department. There are currently approximately 1500 students in the English Department, 320 of which participated in this study. In addition, there are 23 members of staff in the English department, 19 participated in the study (apart from the researchers).

This paper aimed at analyzing the English Departments teachers' and students' perspective of the current SET at the College of Basic Education. The purpose of conducting this study is viewing the weakness and strength of the current evaluation system from the point of view of the students and teachers. Moreover, the researchers' objective was proposing different recommendations that may improve the current evaluation method.

The paper will start at reviewing previous literature in the area of student evaluation of teachers. Definitions will be provided with outcomes of different researches conducted in the same scope. Afterwards, the methodology used in the paper will be revealed in detail. The participants, instruments and data analysis tools will be shown and justified. 
Later, the results will be provided with detailed explanation. The data collected will be entered and analyzed via SPSS using frequency, mean and ANOVA for clear analysis. The discussion will follow, enabling the connection of the literature with the results obtained in order to make good use of the data. Hence, the researchers will provide suggestions to improve the current SET method. This will be followed by a concise conclusion.

\section{Theoretical Background \& Literature Review}

An evaluation, according to Berk, is "the process, whose duty is the systematic and objective determination of merit, worth, or value" (2005, p. 49) and Olatoye and Aanu (2011) add that it is the act of examining something to make a judgment about its value, quality or condition. The process includes two parts: 1. collecting data, 2 . using the data for making decisions in relation to agreed-upon standards. There are many measurement tools (tests, scales and questionnaires) the most widely used are rating scales.

Teacher evaluation, on the other hand, is an evaluation of teachers' performance through a specific period of time done by students. It includes a systematic collection and analysis of information which is used later for making serious decisions regarding the effectiveness or competency of the teacher in achieving certain professional goals (Danielson \& McGreal, 2000; Iyamu \& Aduwa, 2005).

Feldman $(1996,2007)$ states that evaluation instruments try to assess the multidimensionality of teaching. Thus, they should be formed based on an analysis of the content of effective teaching and the reasons for using such instruments, supplied by a literature review and feedback. Germain and Scandura (2005) further add that before developing rating tools there is a need for a clear definition of effective teaching.

\subsection{Effective Teaching}

Teaching is a multidimensional process that is made up of a number of factors (e.g. subject matter mastery, curriculum development, course design, delivery of instruction, and availability to students) (Keane \& Maclathrainn, 2005). Good teaching, however, is the one that aims at facilitating student learning in contrast to "chalk and talk" where knowledge is transmitted to students (Biggs, 2003).

Although those against student evaluations of teaching argue that there is no agreed upon definition of effective teaching, Miller (2009) believes that effective teaching should focus on teaching students how to reason, criticize and question assumptions. It should help students to connect what they learn with other content from other subjects. It teaches them how to be independent learners and how to come up with conclusions. It further helps them to apply what they have learnt to their own lives and how to work with others. A more comprehensive definition of effective teaching is stated by Abrami, d'Apollonia and Rosenfield (2007) when they said that effective teaching can be defined from different perspectives. First, the product definition of effective teaching refers to the positive changes produced in students in related academic domains including cognitive, affective and psychomotor ones. Second, the process definition of effective teaching which focuses on the act of teaching rather than the consequences of those actions includes instructor activities which occur before teaching (e.g. preparation for teaching like reading, choosing activities, setting objectives, selecting a teaching method and designing tests) and during teaching (e.g. organization, enthusiasm, rapport, availability and friendliness). Finally, the process-product definition of effective teaching refers to instructor's activities, which occur before and during teaching and which produce positive changes in students in related academic disciplines including cognitive, affective and psychomotor ones. They further argued that student ratings assess one product of instruction; specifically, student satisfaction with teaching. Instead students' ratings should reflect what teachers do (process) and the effect that have on students (product).

\subsection{Students' Evaluation Content \& Value}

Student evaluations of teaching are widely used in higher education to evaluate teachers' performance. A common student evaluation form uses a likert-type scale for students to rate instructors in relation to a series of statements about the course and about instruction. This is usually followed by a space where students have the freedom to comment in a form of a short essay in case there are some aspects of the teachers' behavior not addressed in the scale or if they would like to clarify or elaborate on their feedback on the first part (Adams, 1997; Beyers, 2008).

Based on the Center for Excellence in Learning and Teaching at Iowa State University (2011) useful student evaluation instruments should: 1. contain open and close-ended questions. 2. include general measures of instructor characteristics (e.g. enthusiasm) and specific instructor behaviors (e.g. providing feedback). 3. useproper scales (e.g. five-point). 4. give useful feedback to teachers that helps to improve their teaching. 5. can be completed in a short time. Abramiet.al (2007) further add that the coding scheme should not be ambiguous but clear and comprehensive. It should contain the bipolar values of a category (e.g. clear and unclear 
presentations). And both the product and the process of teaching should be included in one category.

Student evaluations are vital because learning involves the pupil in the first place as teachers evaluate their teaching based on feedback they get from their students. Teachers also believe that students can contribute a lot to the teaching-learning process knowing that the teaching - learning process is dynamic and changes with time (Gordon, 2001). Students can easily observe teacher behavior and the teaching process and are the best judges of their own learning. Academic leaders have an interest in knowing how well the material is being communicated to students, who better than students to provide that information (McDaniel, 2008). Students' evaluations are an integral part of the evaluation process of effective teaching. An old study by Murray (1997) found that $73.4 \%$ of faculty agreed that student evaluation of teaching results in useful feedback and $68.8 \%$ agreed that student feedback improved teaching. According to Wright (2006) students are seen as consumers interested in the product of college education, thus their opinions are necessary about the quality of instruction at institutions of higher education. Miller (2008) further adds that students should be involved in the process of making the evaluation forms.

Although student evaluations of teaching (SET) are vital to provide feedback on instructors teaching effectiveness, they are not sufficient. Other sources of feedback are needed such as peer or colleague observation, head of department and self-evaluation. However, for a complete picture, all those sources can be integrated (Berk, 2005; Keane \& Macthrainn, 2005). Research on end-of-term evaluations has reported the benefit of student ratings in relation to specific teaching behaviors, but not others. For example, students are the best to judge the clarity of the instructors' oral presentations, his/her ability to organize the material taught and the quality of his/her preparation.

Searching the literature has further shown a controversy where some researchers consider SET valuable and important (Wright, 2006; Roxa, Andersson \& Warfringe, 2007; Burdsal \& Harrison, 2008; Spiller \& Harris, 2013) while others believe that they are subjective and have a negative effect on effective teaching (Murray, 2005; Jacob \& Lefgren, 2008; Spooren, Mortelmans \& Denekens, 2007; Thomas \& Wingert, 2010). Still, everybody agrees that assessing something as multidimensional as the teaching process needs the integration of multiple methods where SET is an integral and vital part (Turpen et al., 2012).

\subsection{Factors that Affect Students' Evaluation}

Many studies have discussed the factors that seem to affect students' evaluation of teaching. Although, some studies have shown positive reliability and validity of SET (Thornton, Adams \& Sepehri, 2010) others have shown that SET does not accurately measure teaching effectiveness (Weinberg, Hashimoto \& Fleisher, 2009; Brockx, Spooren \& Mortelmans, 2011; Sheppard, 2013).

The reason for this controversy seems to be a lack of a clear definition of effective teaching. That's why students find it hard to evaluate teaching effectiveness and administrators cannot be sure what students are evaluating. Teacher effectiveness, as Derek Bok describes it, is an act of faith on the part of teacher and student to do their best (Doyle, 2004).

Not only that, but SET is affected by multiple factors some are related to the teaching context while many others are outside the control of the teacher. Researchers have reported the fact that SET are incomplete and lack in scope (Murray, 2005; Catano \& Harvey, 2011; Hejase, AlKaakour, Halawi, \& Hejase, 2013). For example, Catano and Harvey have questioned the reliability, validity and possible bias that SET may have and Penny (2003) argues that SET are ill-designed thus inferences made are questionable.

The factors that have been reported in the literature and have been known to affect students' evaluation of teaching effectiveness can be placed into two categories: 1. instructor factors 2. course-related factors. Instructor factors include instructor's gender, race, ethnicity, and age (Basow \& Martin, 2012). It was found that teacher gender interacts with student gender and influences student ratings. In a study, where Centra and Gaubatz (2000) asked 741 students from 21 institutions to evaluate their professors, Results showed male professors were rated similarly by their male and female students but female professors were rated higher by their female students. Women are also expected to be more available and more nurturing than men. As to race and ethnicity, African and Hispanic faculty seem to receive lower evaluations than white and Asian faculty. Asking all college students to rate a hypothetical professor based on curricula vita, it was found that African American professors especially women were rated the lowest and Asian professors were rated lower than white professors (Bavishi, Madera, \& Hebl, 2010). Regarding professor's age, it has shown that older faculty may receive lower evaluations compared to younger faculty. For example, Arbukle \& Williams (2003) asked students to look at a slide show of age and gender stick figure and listen to a neutral voice presenting a lecture in order to evaluate the stick-figure instructor. The young male professor had significantly higher ratings than the young female professor. As to instructor 
attractiveness, Students were seen to give high scores to good-looking instructors as well as easy instructors (Felton, Mitchell \& Stinson, 2004; Kogan, Schoenfeld-Tacher \& hellyer, 2010). Using student ratings from the website ratemyprofessor.com, Riniolo, Johnson, Sherman and Misso found those teachers with higher scores on the attractiveness scale also had higher scores on teacher effectiveness. Regarding popularity of the instructor, students seem to give high ratings to popularity rather than effective teaching. Highly entertaining instructors tend to receive higher ratings too.

Course factors, on the other hand, include expected grade where instructors known as easy graders usually receive higher ratings (Keane \& Maclathrainn, 2005; Surratt \& Desselle, 2007; Weinberg et al., 2007). This may lead to grade inflation where teachers, for the sake of higher ratings, tend to give higher grades for students who do not deserve them. Another course-related factor is course difficulty. It is argued that instructors may reduce academic content knowing that course workload affect students' ratings of instructors (Surratt \& Desselle, 2007; Carrell \& West, 2010; Thornton, Adams \& Sepehri, 2010). Other factors include content and coverage of the items included in the evaluation tool. Poorly worded or ambiguous items would not provide valuable feedback to teachers or administrators (Kalayci, 2009). Another important factor is the emotional state the student is at when filling out the form. Anxious, angry and depressed students would give lower scores to teachers even if they were effective teachers (Miller, 2008). Other factors such as class time, class size, subject area, course workload, course leveland academic discipline were found to have an effect on students' ratings of instructors.

The most important factor according to Murray (2005) Noakes (2009) and Doyle (2004) is the fact that students do not have enough background knowledge to assess factors such as course design, instructor knowledge, academic standards, and quality of assignments. According to Murray (2005) students can only evaluate what they can observe. This results in inadequate evaluation of teacher effectiveness.

Moreover, some students were reported giving little thought to the evaluation process as they rush through the form to finish quickly and attend to something else like talking with their friends or finishing their assignments. For them, it is another task that they have to do (Beyers, 2008). Also, students do not believe that their feedback is taken seriously. Most importantly, the timing of the evaluation is usually towards the end of the term where students are under pressure to hand in their assignments and prepare for their final exams. The end result is that students write down their feedback hastily without giving it enough thought (Weimer, 2012). And Zhang (2004 in Sprinkle, 2008) adds that students' ratings are affected mostly by whether the instructor's teaching style matches the student's learning style.

\subsection{Empirical Research}

Students' evaluation of teaching (SET) has been one of the areas thoroughly researched (Lattuca \& Domagal-Goldman, 2007; Surratt \& Desselle, 2007; Brown, 2008; Kogan et al., 2010; Kozub, 2010; Catano \& Harvey, 2011; Machingambi \& Newman, 2011; Lekena \& Bayaga, 2012; Turpen et al., 2012). Still, the literature has shown to be inconsistent where some studies value student evaluations of teaching and see them as reliable and valid while others criticize them and consider them inadequate and a threat to academic quality.

\subsubsection{Students' Perception}

To examine students' comments and ratings of 626 professors teaching different disciplines at a U.S. university at RateMyProfessor.com using a survey and a focus group interview, Kindred and Mohammed (2005) found that students' comments focused on the professor's competence including clarity of instruction and personality traits such as focused, energetic, inspiring, helpful and easy. Overall, students' concern was for teacher competence more than appearance or personality. They concluded that students are concerned more about the quality of instruction, competence, knowledge, clarity and helpfulness more than appearance and personality.

Similarly, Silva, Silva, Quinn, Draper, Cover and Munoff (2008) wanted to describe what American and Canadian students were saying about their professors on RateMyProfessots.com and RateMyProfessors.ca. They looked at 636 instructors' evaluations from 100 colleges and universities in the U.S. and 478 instructors from 45 universities in Canada reaching a total of 6140 student evaluations. Findings showed students giving more positive comments about their courses and professors. Interestingly, more focus was on instructor's characteristics like enthusiasm, organization, knowledge and least on student development. Also students' ratings correlated with instructor's appearance. Attractive instructors received higher ratings. However, Americans made more positive comments about their professors' personality, helpfulness and clarity. Factors that matter were enthusiastic, knowledgeable, respectful to student, helpful and clear.

While the above studies investigated students' opinions of their instructors, Kalayci (2009) wanted to assess the reasons given by 138 junior Turkish students from three departments at Gazi University for their ratings to the 
closed-ended items in the questionnaire. Three male teachers volunteered who had 10 years of experience. Using a questionnaire, Kalayci found that the reasons students gave for their ratings were not related to the questions. There were differences in the perception of the same item to the same teacher by different students of the same class. There were contradictions in students' reasons even for items assumed to be clear cut. Students rated the same item differently although they gave identical reasons. Students also gave identical ratings of the same class and for the same teacher but with different reasons. Students of the same class rated same items differently although giving identical reasons. Kalayci concluded that subjective influences in individuals' understanding of the problem might explain the differences in the results. Surprisingly, students rated even situations that they could not remember or could not be certain about.

To measure the awareness and utilization of RateMyProfessors.com website and to measure its internal and external validity, Davison and Price (2009) surveyed 216 students at Appalachian State University in North Carolina and found that students give higher ratings to instructors who give easy courses. They prefer low workload classes, cancelled classes, and little effort required to get an A. They further reported that teacher's personality affect the ratings where student-centeredness comes first followed by entertainment then expertise and preparedness for class. Similar to Brown (2008), results suggest that the information provided by RateMyProfessors.com website is not valid. It lacks external validity. The website is missing statements related to the learning process or knowledge acquired. Not having a broad measure of teaching effectiveness affects the internal validity of the information gained from the website. Even the open-ended comments do not focus on teaching effectiveness, but instead focus on easiness. Thus, they do not evaluate the instructor's ability to teach. They should be informative and prompt necessary pedagogical change. They should also be relevant to the discipline. How much students learned and instructor's expertise should come first. It suggests students today are not interested in learning; they need a degree without an effort.

In a more recent study to measure students' perceptions of the effectiveness and appropriateness of the evaluation process in Lebanon, Hejase et al. (2013) surveyed 418 university students from different universities. Overall, students had positive attitudes towards SET. They believed that the questions are well designed, clear and relevant to what goes on in the classroom. However, more than half of the students reported that the questions were too long and some believed that SET doesn't cover all evaluation criteria. Students further reported their ability to judge their instructors and that instructors use SET to make improvements. But, they reported that instructors change their behavior to receive higher ratings or give lower grades as a result of poor ratings. More than half of the students do not believe SET scores reflect effective teaching and half of the them say that they are serious, fair and accurate while half of them do it because it is a university requirement. Overall, students had positive view on the format and content of SET. However, they complained about the length and that it doesn't cover all evaluation criteria. Overall, the majority does not trust SET ratings to reflect effective teaching and most students do the SET just because it is a requirement.

\subsubsection{Instructors' Perception}

Not only students' perceptions were investigated, instructors' perceptions of students' evaluation of teaching effectiveness received similar importance. To investigate 101 Hebrew and Arab instructors' attitudes towards student evaluations at a teachers' college in Israel using a questionnaire, Nasser and Fresko (2002) found that instructors believed that difficult courses will receive lower ratings. They believe that students' ratings reflect how nice an instructor is. Teachers agreed that students' ratings were useful in improving instruction, especially the written comments on open-ended questions. Only a few instructors reported doing some major changes in their teaching based on students' comments such as type of assignments, organization of a course and strategies used. However, rare changes were done to grading or difficulty of the course. Nasser and Fresko concluded that instructors' showed a moderately positive attitude to the validity of student ratings. There was a great variability between teachers; some agreed others disagreed. Overall, teachers do not agree to the fact that students' ratings should be used for making decisions regarding teachers' promotion. It was found that those who received higher ratings are the ones more positive towards students' evaluation.

On the contrary, in Nigeria, Olatoye and Aanu (2011) surveyed 250 teachers to find out about their perceptions towards using students to evaluate their teaching effectiveness found the majority of teachers in favor of students evaluating teaching effectiveness. No differences were found between male and female teachers in their attitudes. Differences were found in districts where rural teachers were more in favor to using students to evaluate their teaching effectiveness. Olatoye and Aanu concluded that teachers have a positive opinion of using students to evaluate teaching effectiveness.

In a more recent study to explore the impact of student evaluations of teaching on university academic staff 
experiences and their professional development, Lekena and Bayaga (2012) surveyed 50 lecturers and interviewed 10. Similar to Olatoye and Aanu (2011), lecturers reported that the feedback they received from students is useful for their professional development. It helped them reflect on their teaching process. However, others said that student evaluations of teaching is not useful, on the contrary, they have a demoralizing effect, lack logical ground, affect student-teacher relations and are contradictive. Still, they agree to using them for promotion purposes. Those who think SET are useful see SET as an aid for their professional development and inspiration. They further recommend that SET be flexible instead of being rigid or mandatory. They further state that SET mainly has an effect on the content of the course, its structure, the teaching style and methods used.

In the light of the instructors' opinions and attitudes towards student evaluations of teaching effectiveness, the American University of Beirut (AUB) (2005) asked 145 faculty members from five faculties at the AUB to fill out an online questionnaire. Results showed only a few teachers agreed to use evaluations for promotion. More than half believe that faculty members change their teaching to receive higher ratings and that the ratings result in negative consequences and reduce faculty ethics. They further believe that a heavy workload in a course will result in lower evaluation. They also believe that students do not take the evaluation process seriously. About half of faculty believe that students do not have enough background to judge quality of instruction. As to the open-ended comments, instructors reported that some items were not clear or not related to the courses and thus are not useful. They believe that difficulty of course affects evaluation. They also believe that students are not serious in their evaluation; they are not mature or responsible enough. Their evaluations are influenced by the workload and the expected grade.

In a similar study, Turpen, Henderson and Melissa (2012) wanted to find out about faculty's perceptions of the methods used to evaluate teaching effectiveness. They interviewed 35 teachers and surveyed teachers across the country. Findings indicated very few teachers satisfied with their institution's methods for assessing teaching effectiveness. They reported using their own informal SETs, but with different questions for their students. They also said that they skim the multiple-choice items of the survey and focus on the long answer comments of their students. They emphasized that their institution relied mainly on SETs to measure teaching effectiveness. They further believe that the questions in SETs do not measure or cover the range of goals that they have in their courses e.g. problem-solving, understanding culture and critical thinking. Overall, teachers are skeptical as to the use of SETs and prefer to use their own methods like students' test performance and on-going formative assessment.

As seen above, the literature on students' and teachers' perceptions reveals a controversy. Most of the studies are inconsistent in their results. This might be the result of factors, which are believed to play a role on student evaluations of teaching and teachers' perceptions of students' evaluations. Sprinkle (2008), for example, wanted to find out how biases toward professor traits (e.g. age, gender, teaching style, rank, personality and grades awarded) affect students' judgments of effectiveness. In a survey of 202 undergraduate students, Sprinkle found that students perceive professors closest to their age as more effective. Older students seem to prefer male professors while younger prefer females. Also, female students prefer female professors and male students prefer male professors. Older students prefer older professors while younger students prefer younger professors. Students also seem to give higher ratings to professors who transfer information in a manner that is similar to their learning style. Interestingly, older students prefer lecture style while young students prefer use of technology and those who like to work alone prefer computers as they reduce face-to-face interaction.

As expected, the literature above has mostly shown teachers and students dissatisfaction with the SETs used at universities and colleges. Most of the skepticism was the result of factors that are either related to students or to their instructors and sometimes to the course itself or even to the SETs. Thus, some researchers went a step ahead into designing a whole SET. For example, Catano and Harvey (2011) aimed to develop new student evaluation of teachers' scale involving students. They recruited 65 undergraduate senior-level university students studying a variety of disciplines. They tried to focus on the competencies that students considered to be important for teaching effectiveness and similar to the ones teachers provided. Accordingly, students chose "problem-solving", "availability", "communication", "creativity", "professionalism", "social awareness", "conscientiousness", "feedback", "individual consideration", as important to them. Interestingly, there were similarities and differences in the criteria for teaching effectiveness suggested by both students and instructors.

Most of the literature on student evaluations of teaching has mainly focused on the issue of reliability and validity. Research indicates that a large number of the questions on the student evaluation forms are either unclear, subjective, ambiguous or unrelated to classroom practice (Wines, 2006). Added to that is the fact that faculty perspectives and emotions regarding students ratings of instruction haven't received enough attention in empirical research (Kogan et al., 2010). Similarly, very few studies have investigated students' opinions of SET 
(Patrick, 1997; Anderson, Ingram \& Buford, 2012). It is important to find out about student and faculty perceptions of SET knowing that faculty are dissatisfied and are skeptical of the way SET is conducted (AUB, 2005). The fact is that both students and instructors work together in giving meaning to the course. Thus, faculty should have a voice and an active role in the evaluation process, which might result in their acceptance of SET. Only when instructors understand and value SET, it will be really effective. There is also a need to explore the ways of conducting SET in a more effective and meaningful way.

As to Kuwait, the online student evaluations of teaching (SET) effectiveness form focuses on quantitative feedback. This study is designed to shed the light on the experience of the College of Basic Education in Kuwait on the topic of student evaluations of teaching effectiveness (SETs). The reason students and teachers from the English Department were chosen to participate in this study was to find out whether teacher evaluation should be tailored according to the course being evaluated or general evaluations (as currently applied) were suitable. As most teachers complain about SETs and since it is becoming central in the teaching evaluation process and used to make decisions regarding faculty promotion, it could not be ignored. Findings could contribute to the improvement of SET systems currently in use in colleges and universities. Research implications may also help colleges and universities in developing clear and well designed evaluation forms.

Suggested Research Questions:

1) What are college students' perceptions of the current student evaluations of teaching effectiveness form?

2) What are faculty perceptions of the current student evaluations of teaching effectiveness form?

3) What do faculty believe of students' evaluating their teaching effectiveness?

4) On what criteria do students give high ratings to their instructors?

5) Are there differences between students in their perceptions of SETs based on their age, GPA, major, nationality and grade level?

\section{Methodology}

\subsection{The Participants}

The questionnaires distributed to students were approximately 370 , out of which 320 questionnaires were chosen, as they did not miss important data. The participants in this study were undergraduate students in the English department in the College of Basic Education in Kuwait (CBE hereafter). The students participating were all female (as there are no male students in the English major). The students were chosen randomly; the only condition for participation was being an English major student. Moreover, 19 members of staff in the English Department also participated in filling in a questionnaire, specifically tailored for members of staff. This number represented all the members of staff in the department teaching in the semester the study was applied.

\subsection{Instruments}

Data collection was initially based on two 20-statement questionnaires with two open-ended questions in each. One questionnaire was designed for students, while the other was designed for teachers. In the beginning of the students' questionnaire, the participants were asked about their age, year of study in CBE, social status and GPA. These variables helped later to connect answers to social and academic factors, and it also helped to pinpoint the reason certain differences occurred. Both questionnaires were written in the participants' first language. This would ensure the complete understanding of all statements.

The questions were set to tackle several issues in the teacher evaluation form from the perspective of students and teachers in the English Department. The issues tackled were clarity of statements, accessibility of the evaluation - by teachers and students, the importance of the evaluation, the fairness of the outcome, and whether the statements cover important academic areas. The statements were divided, for statistical analysis, into three main groups: clarity of the evaluation form, ease of access, and importance of the evaluation. The statements and their categorisation can be found in appendix (A).

The answers were set from totally agree to totally disagree on a 5-point Likert scale. The researchers found the addition of a $6^{\text {th }}$ scale stating "I don't know" important for the reliability of the answers since it insured that any missing answers were not left on purpose, and participants could choose this option if none of the answers were suitable in their point of view.

The open-ended questions for both teachers and students asked about any more advantages and/or disadvantages of the current online evaluation system used in the College of Basic Education. This should help in obtaining further detail on the use of the evaluation form in college. 


\subsection{Data Collection and Analysis}

The data was collected through the distribution of two questionnaires: one for the instructors, and the other for the students. The students were randomly chosen from different study years in college. After the collection of the questionnaires, the data was analysed using SPSS to find out the mean, frequency and minimum/maximum range. Significance was calculated as well, especially where independent variables such as age, year in CBE, and GPA are concerned. The open-ended questions were manually analysed. The number of participants in the open-ended question was less than the overall number of participants, as many participants did not feel the need to add more advantages or disadvantages. The statements in the evaluation were calculated individually and then the grades were accumulated to an average. The instructors, hence, would be able to identify the points of strength and weakness, and try to address the points mentioned, which scored less.

\section{Results \& Discussion}

The results were divided into two main categories: students' questionnaires and teachers' questionnaires. The questionnaires were analysed, where the 20 statements and the two open-ended questions were analysed individually.

\subsection{Statistical Results}

\subsubsection{Students' Questionnaire}

The following analysis is based on results of the students' questionnaire.

\subsubsection{The Statements}

The statements in the questionnaire were divided into to the three main groups (refer to instruments of the study). The first category "Clarity of the evaluation" contained five statements the majority of which were answered with "Disagree" or "Disagree completely". More than half the students $(57.5 \%)$ believed that statements were not clear as opposed to $14.1 \%$ who believed the statements were clear. Moreover, $45.8 \%$ believed that the statements did not cover all aspects that need to be covered, while $20.9 \%$ thought they did. This was also supported by statement number 18, "I don't feel the need to mention anything more", where $57.4 \%$ of the students did not agree. This shows the need of students to add more information, preferably in a comment space. Notably, in these first two statements the percentage of partial disagreement/agreement was quite high $(27.5 \%$ and $32.5 \%$ consecutively). This may indicate less confidence of the student's point of view. The students were not completely sure of the clarity of statements nor were they sure that they needed space for comments. This, in fact, might reflect the lack of importance of the evaluation process in the students' viewpoint.

The most shocking result was the high percentage of disagreement in adding a statement on the use of technology in class, as the researcher felt it would be a main requirement for the current generation. To support this finding a statement was added to insure reliability, which states "I would like a statement on the use of technology for communication". It was found that $66.7 \%$ of the students did not agree, of which a high $44.2 \%$ disagreed completely. This shows that the use of technology is not valued much by students. In a two-way ANOVA test by GPA by year at CBE significance was found where $p=0.402$ "Where $p$ equals or is less than 0.05 ". This significance was found as the students with lower GPA and fewer years of study in CBE were careless about the use of technology in class. As shown below in Figure 1, students and teachers seem to significantly disagree on the importance of the use of technology in class.

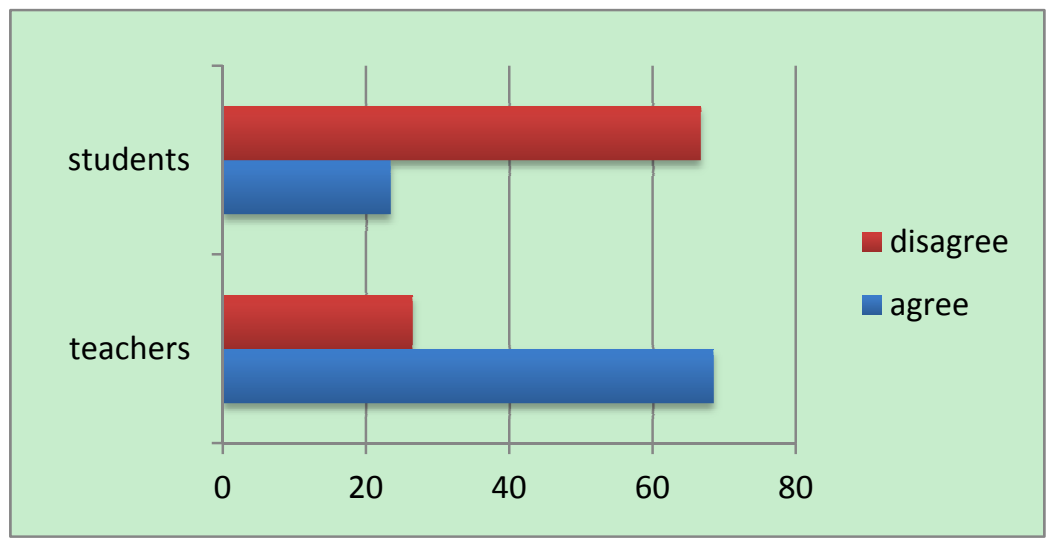

Figure 1. teacher and student response to "I would like a statement on the use of technology in class" 
Accessibility and the ease of using the online evolution was the second category to be analysed. When students were asked about the ease of accessing the evaluation form, $58.3 \%$ of the students believed that the form was not easy to fill in, as opposed to $25.9 \%$. Yet, $44.2 \%$ of the students did not prefer to evaluate the teachers in the student's union site rather than the official CBE site. Only $29.2 \%$ of the students stated that they do not fill in the form because it is difficult to access the system. It is believed that most students fill in the form because they feel that they could write everything they wish in the current evaluation form. Hence, $43.3 \%$ disagreed to the statement "I can't write everything I wish about a teacher in the current evaluation form", while $25 \%$ agreed to the statement. In a multivariate ANOVA test, significance was found by GPA $(p=0.027)$ as students with higher GPA agreed with the statement. In addition, a T-test by social status and year in CBE was conducted to find significance at $\mathrm{p}=0.034$. It was found that older students who were divorced completely agreed with the statement. High significance was also found in statement number 12 "I prefer to evaluate teachers in the student union site", where a T-test by social status and GPA showed significance $p=0.047$. A multi-ANOVA test by age by social status by GPA showed significance of $p=0.042$. Many students did not agree that filling in the form takes a lot of time (44.2\%); however, $25 \%$ partially agree, and this is found to be a very high percentage.

The importance of the evaluation consisted of 10 statements. The statistics showed that $47.7 \%$ of the participants did not believe that the evaluation is the best way to evaluate teachers. Furthermore, $52.5 \%$ do not believe that filling in an evaluation form gives them a chance to express their own opinion as opposed to a mere $26.7 \%$ who believe otherwise. Even more surprisingly, $62.5 \%$ of the participants disagreed that filling in an evaluation form made them feel their importance as students. The majority of students do not think that teachers care about the evaluation (58.3\%). Uncertainty was found in answering the statement "Teachers see the scores after grading the students" where disagreement equaled $39.2 \%$, agreement $29.2 \%$ and partial agreement/disagreement $27.5 \%$. This certainty is also reflected in the statement "I'm not completely honest because of the fear from the teacher's response" as disagreement, partial disagreement, percentages were very close. This shows that the students are not sure that the evaluation is completely anonymous and therefore they were not sure if they could fill it in as they would like.

Table 1. Results of "I'm not completely honest because of the fear of the teacher's response"

\begin{tabular}{lllll}
\hline & Frequency & Percent & Valid Percent & Cumulative Percent \\
\hline Don't know & 14 & 4.4 & 4.4 & 4.4 \\
Disagree completely & 59 & 18.4 & 18.4 & 22.8 \\
Disagree & 66 & 20.6 & 20.6 & 43.4 \\
Partially agree/disagree & 88 & 27.5 & 27.5 & 70.9 \\
Agree & 53 & 16.6 & 16.6 & 87.5 \\
Completely agree & 40 & 12.5 & 12.5 & 100.0 \\
Total & 320 & 100.0 & 100.0 & \\
\hline
\end{tabular}

As seen in Table 1, most students partially agree/disagree to the statement

Most students connected grades with the evaluation; although $38.3 \%$ of the students stated that their answers depended on their grades, $50 \%$ of the students stated that they evaluate teachers according to their grades not their teaching. This shows that the majority of students fill in the evaluation form in the light of the grades they have received. In addition, $43.3 \%$ of the students stated that they would give a better evaluation for a teacher who promises a better grade. In this light, significance was found in the statement "my answers depend on my grade" in an ANOVA test by social status where $\mathrm{p}=0.025$, as widowed participants disagreed completely. In addition a T-test by age and social status shows significance of $\mathrm{p}=0.050$; and a multi-ANOVA by age by social status by GPA showed significance $\mathrm{p}=0.041$ as the oldest age group students with lower GPA agreed completely. Furthermore, significance was found in the statement "I evaluate teachers based on my grades", of $p=0.043$ (By age by social status by year in CBE). A large number of students agreed that their mood affected their answers (45\%), yet $35.8 \%$ disagreed. Significance was found in the statement in two multi-ANOVA tests. The first was conducted by age by social status by year in CBE where significance was found at $\mathrm{p}=0.032$. Significance was also found by age by GPA by year in CBE, where $p=0.021$. It was found that younger students with lower GPA agreed the most. 
The statistics generally showed that students did not believe that the evaluation is easy to fill in. Moreover, they did not feel the need for more space to comment. In addition, most participants did not believe that the addition of technology as a criterion in the evaluation form is important. Clearly, grades and mood affect the evaluation enormously. An overall view of the questionnaire reflects uncertainty in different aspects of the evaluation as many statements were answered by partially agree/disagree by many participants.

\subsubsection{The Open-Ended Questions}

Although 320 students participated in this study, only 87 students answered the open-ended questions. The advantages the students wrote were half the number of the disadvantages. Surprisingly, most students seemed to agree on the same advantages and disadvantages.

The students were most happy to participate in the evaluation as they felt their importance as members of the educational system. It "emphasizes the students' role in the educational system" a student stated. They felt that their participation would help the teachers improve and change according to the evaluation scores. In addition, many students felt that when they evaluate the teacher, they give new students a chance to know more about the teachers before registration. Furthermore, many students found the system easy to access, and the evaluation form easy to fill-in. This meant that most students did not feel it took time or was difficult to access.

However, many students asked for some improvements on the form to make the evaluation more useful. For example, a large number of students $(n=63)$ wished that attendance and office hours were evaluated. It seemed to be the most important point from the student's viewpoint. One student wrote, "Behavior is not well addressed". In addition, some students felt that some statements were not clear or were very general. They felt that they had more to say in relation to a few statements but could not. To solve this problem, many students-as did teacherssuggested an open space for comments to add what they felt was missing.

Other problems mentioned were students' exaggeration and fear of telling the truth. Some students believed that their social interaction with a teacher affected their evaluation. Therefore, students would give an excellent score for a teacher who would promise to "help" them grade-wise even if his/her teaching is not good. Moreover, a few students $(\mathrm{N}=13)$ believed that the students' moods affected their evaluation. Hence, if a student was evaluating a teacher and did not do well in an exam, that teacher would not get a fair evaluation. Fear, on the other hand, was also a problem for a small number of students. Three students stated that they believed teachers could see their evaluation. This belief meant that they would not only make sure they would fill in the evaluation form, but they would also give the teacher excellent scores to make sure the teacher would give them good grades in return. This brings back the point the teachers have made above, if students attend a workshop on the evaluation process, the fear of being honest will disappear.

\subsubsection{Teachers' Questionnaire}

The data obtained from 19 teachers' questionnaires was entered in SPSS. Two questions, however, were analysed by manual calculation, as they were open-ended questions.

\subsubsection{The Statements}

The statements tackled many issues of teaching, and they could also be divided into three main categories. The first category was concerned with statements themselves; were they easy to understand? Did they cover all aspects of teaching? etc. The second category tackled the accessibility of the evaluation and the ease of following up. Teachers were given statements on how easy it was to follow up the filling up of the evaluation forms, while keeping the information discrete; and how willing and competent students are to fill in the forms. Finally, the third category was concerned with the importance of having a teacher's evaluation. For example, did teachers think having an evaluation was important? And why was it important?

Five statements belonged to the first category "clarity of statements". The first statement was "the statements are clear". Where $68.4 \%$ of the teacher participants agreed that the evaluation criteria were clear, as apposed to a mere $5.3 \%$ who did not agree. The percentage of disagreement was very low, which would mean that 1 out of 19 teachers believed that the criteria for evaluating teachers in the evaluation form were unclear. The participant teachers also generally agreed that the statements covered all academic aspects. However, when asked if they would like to add a statement on the use of technology in class, $68.4 \%$ agreed, where $42.1 \%$ of which completely agreed. Hence, as expected, most teachers would like to add a statement in the evaluation on the use of technology to communicate with students, for academic purposes

As for the access criterion, it consisted of four statements. Two statements asked whether students were competent to fill in an evaluation form, and whether students usually would fill in an evaluation form. It was found that $47.4 \%$ of teachers did not believe that students are competent and can fill in the evaluation form 
wisely, as opposed to $30 \%$ who agreed that they were competent. The majority of teachers also believed that the students did not bother to evaluate their teachers $(68.4 \%$ of the participants).

On the one hand, many teachers believed that the system is easy to access in order to follow up on the scores and results. On the other hand, many teachers did not believe that the evaluation is discrete. Surprisingly, $10.5 \%$ did not know if the system was discrete. The uncertainty of the discreteness of system was reflected clearly in this statement.

Table 2. Results of the statement "The evaluation is discrete"

\begin{tabular}{lllll}
\hline & Frequency & Percent & Valid Percent & Cumulative Percent \\
\hline don't know & 2 & 10.5 & 10.5 & 10.5 \\
disagree completely & 4 & 21.1 & 21.1 & 31.6 \\
disagree & 2 & 10.5 & 10.5 & 42.1 \\
partially agree/disagree & 1 & 5.3 & 5.3 & 47.4 \\
agree & 7 & 36.8 & 36.8 & 84.2 \\
agree completely & 3 & 15.8 & 15.8 & 100.0 \\
Total & 19 & 100.0 & 100.0 &
\end{tabular}

As seen in Table 2, although many teachers seem to be uncertain, the majority felt the evaluation was discrete.

The third category consisted of eleven statements, which were all concerned with the importance of having a teachers' evaluation. $31.6 \%$ of the teacher participants partially agreed that the evaluation was an important method to evaluate teacher's performance. Moreover, the same number of participants did not believe that this evaluation was the best way to evaluate teachers. However, more than half the teachers believed that the evaluation is an opportunity to learn from the students' answers $(52.7 \%)$, and that the evaluation included suggestions that would help them improve their teaching (where $52.6 \%$ agreed). Yet, only $36.8 \%$ of the teacher participants cared about the evaluation outcome. The reason behind this was their uncertainty of the reason and method of filling up the evaluation forms.

Table 3. The results for the statement "students evaluate me according to their grades"

\begin{tabular}{lllll}
\hline & Frequency & Percent & Valid Percent & Cumulative Percent \\
\hline disagree completely & 1 & 5.3 & 5.3 & 5.3 \\
disagree & 1 & 5.3 & 5.3 & 10.5 \\
partially agree/disagree & 3 & 15.8 & 15.8 & 26.3 \\
agree & 5 & 26.3 & 26.3 & 52.6 \\
agree completely & 9 & 47.4 & 47.4 & 100.0 \\
Total & 19 & 100.0 & 100.0 & \\
\hline
\end{tabular}

As seen in Table 3, very few teachers disagreed that the grades affected the results of the evaluation.

Unfortunately, the majority of the participants believed that grades were the key to a good evaluation. $73.7 \%$ of the participants agreed that students evaluated teachers according to their grades, and $57.9 \%$ felt that many teachers gave better grades than deserved to get a good evaluation score. Additionally, $52.7 \%$ of the participants believed that teachers covered less material to make the course easier and the grades better and get a good evaluation. Hence, the majority of teachers have shown that they believed that the evaluation was a mean of getting better grades. So, if students did not like their grades, they would give a bad evaluation regardless of the teacher's effort. 
Two statements in the third category asked about the effect of the students' mood on the evaluation. The majority of participants partially agreed that the students' mood affected their answers in the evaluation form (where the results were $42.1 \%$ and $31.6 \%$ consecutively). Again the issue of doubting the students' ability to fill in an evaluation form reappears. Teachers seemed to have serious doubt towards the students' attitude in filling in the online evaluation form.

\subsubsection{The Open-Ended Questions}

In the open-ended questions, 13 out of 19 teachers left their feedback. Most comments were against the evaluation one way or another. The advantages of the evaluation, although were very few, stressed the benefits teachers could make out of the evaluation. One of the most repetitive advantages of the evaluation was that it would help teachers view their weakness in the students' eyes, which might help them improve their teaching. One instructor stated that "(teachers) would not see their own weakness unless it was pointed out", and once it was pointed out, he/she "would try hard to make that weakness disappear". In the same light, some instructors believed that the idea of being evaluated made them work harder to avoid criticism.

Half of the participants also felt that an evaluation is important for the students. One of the participants commented that evaluations "would give students a sense of belonging". In addition, another instructor felt that when students are given the right to evaluate "they would believe in making their college a better place". However, two comments insisted that there should be reward and punishment, which will make both teachers and students take the evaluation more seriously to view its benefits.

Other advantages were technical. For example, some teachers believed that the ease of accessing the online evaluation request and review is very encouraging. Others thought that since teachers did not administrate the filling in of the evaluation, it held more value and was more reliable.

The disadvantages of the current teacher evaluation applied in the college of basic education were many and repetitive. The most repetitive disadvantage was the idea that students did not take the evaluation process seriously. Some instructors believed the weak students might find the evaluation as a way to get back to teachers who would give them low grades. Others believed that some students did not read the statements and tick one answer all the way. One instructor stated, "it's all about grades. Teachers give them high grades to get good evaluations, and low grades mean a bad evaluation". Many seemed to agree ( 8 teachers). The connection between the evaluation and grades seemed to be the issue that worries teachers most, yet it is not the only issue.

Another main disadvantage in the viewpoint of teachers is the lack of experience students have in the evaluation area. Five teachers requested a workshop to teach students the importance and method of evaluation. One teacher commented that students should not evaluate teachers as "the less educated should not evaluate the person that holds a higher degree". Two teachers believed that the results should not be taken seriously if students were not trained. However, if the students received training to fill up the evaluation form, a few technical problems would still need to be addressed.

A few technical issues need to be addressed to make the evaluation process better, according to the teachers' comments. One of these issues is the fact that the number of students evaluating the teacher was not counted for. Hence, if a class consisted of 60 students, and only one student evaluated the teacher giving him full points on all statements, the teacher would get a straight A (4.00). Many teachers (10) noticed this flaw in the system, and one added, "many teachers don't inform their students of the evaluation and only choose to inform the one student they know would give them a good evaluation". Another flaw that nine teachers found was the fact that the evaluation did not give students space to add a comment. "The evaluation does not cover all teaching features, like the use of technology" as one teacher stated, thus, again appears the need for the space for comments.

Some items were not covered because each department has its own courses and methods of teaching. This was a disadvantage that four teachers mentioned in the questionnaire. They believed that either a comment part should be added, or even better, each course should have a tailored evaluation to cover all the aspects that need to be covered.

Finally, a few teachers hoped the evaluation would start late and last for more than a month. Moreover, some teachers believed that teachers should be able to see the names of the students who did not fill in the evaluation form to encourage them to take part in the evaluation process. Not knowing who evaluated made it difficult for teachers to get the feedback from all his/her students.

\subsection{Discussion}

Although students' evaluation of teachers is not a new concept, it still, in many institutes, does not seem to cover the aspects it needs to cover. The evaluation system in CBE is accessed, by both teachers and students, online. In 
all, there are 32 statements that should be answered on a five-points Likert scale starting from "completely agree" and ending at "completely disagree". The questionnaire was designed by specialist in the Evaluation and Measurement department in the Public Authority of Applied Education and Training; with the assistance of a few faculty members from different colleges and departments affiliated with the Public Authority of Applied Education and Training.

This study started with Doyle's (2000) statement that there is no agreement on what makes a good teacher. If this was true, there would be no or little agreement between teachers and/or students to what makes a good teacher. In the current study, $68.4 \%$ of the teachers agreed that technology should be considered and add in a statement in the evaluation form. On the other hand, most students did not believe that adding technology is important. The study has shown, therefore, that there was no agreement on what effective teaching is. Is the use of technology an important element of effective teaching? One should also consider the fact that by time technology has become more important. Not only that, but technology has also changed to be portable and easy to access. Thus, updating the evaluation form might be a need, as some teachers would feel they needed to be identified as "better teachers" for being up-to-date.

Another problem that might face students while filling in an evaluation form is the fact that there is more information that the student would like to share. The majority of teachers suggested that there should be a comment space added in the evaluation form to encourage students to write more information on things that were not mentioned in the evaluation. Although the students did not encourage more space in the statement "I don't need to mention anything more" as $57.4 \%$ agreed. Yet, many students in the open ended question asked for a comment space to add more information on what they believe is effective teaching. Many studies have shown that open and close-ended questions in an evaluation are a must. A study based on the Centre for excellence in learning and teaching at Iowa State University (2011) showed that one of the main elements of any student evaluation form is having an open ended question. That being said, the evaluation form in CBE seemed to lack one of the main elements of a good evaluation form. Another element that the evaluation form was lacking was clarity. Most students who participated in the study believed that the statements were unclear. This issue should also be addressed and the statements should be clearer for students.

On the other hand, the evaluation at CBE has shown to include other important elements mentioned by the Centre for Excellence in Learning and Teaching, such as, can be completed in a short time, uses proper five-point scale, and gives useful feedback to teachers to improve their teaching.

Although Gordon (2001) believes that student evaluations are vital because learning involves the pupils in the first place, most teacher participants in this research do not believe so, as they believe students are not competent enough to evaluate teachers. Since - as mentioned previously - students do not have space for comments, and the majority think statements are not clear, responses could not be considered reliable. The issue of the lack of clarity from the students' point of view, and lack of coverage of all academic aspects might reflect an ill-designed evaluation form. Many researchers question the design of evaluation form in term of validity, reliability and even possible bias (Murray, 2000; Catano \& Harvey, 2011; Hejase, Alkaakour, Halawi, \& Hejase, 2013 among others). Penny (2003) commented that since evaluation forms are ill-designed, references to it are not valid.

Many students believed that the evaluation form is missing out on a very important issue; namely, attendance and office hours. In addition, some teachers felt that the statements should be course-tailored. As English language teachers, many felt that their language fluency and command was an important factor not mentioned in the current evaluation. Generally, there seemed to be consensus that the evaluation form needed to be designed differently to accommodate for the needs of both teachers and students. Kalayci (2009) found that poorly worded or ambiguous statements did not provide valuable feedback to teachers. This has been said, if the statements were poorly written each student would understand them differently, and thus, the responses would lose their sense.

If the evaluations would cover all the aspects they feel are important, students will be more willing to participate in the evaluation process. Currently, $68.4 \%$ of the teachers believed that students did not bother fill in the form

Teachers of CBE could see the number of participating students on the website, yet they could not see the names of the participants. Hence, finding a small number of participating students gave them less interest in the evaluation. Although a few teachers stated that they cared about the evaluation's outcome, half the teachers stated that they work harder to avoid criticism. On the other hand Bayer (2008) found in his study that students rushed through the evaluation and did not take it seriously. In the current study, 58.3\% of the students strongly believed that teachers did not care about the outcome of the evaluation. Weimer (2012) believed that having the 
evaluation at the end of the term, in the time when students hand in homework and projects, and when they start studying for the final exams was also a factor that hinders participation. This shows that many factors encouraged students not to participate in the evaluation. It's worth noting that the students of the highest GPA cared most about the valuation. They significantly believe, more than the other participant that filling in an evaluation reflected the importance of students who are an important part of the academic structure.

Many teachers also took the results of the evaluation less seriously because they believed students were not competent enough to fill in a teacher evaluation form. Hence, they recommended a short training course that might stress the importance of the evaluation system and show the methods of filling it in. Many researchers found that first year students did not have enough background knowledge to assess factors such as course design, instructor knowledge and academic factors (Doyle, 2004; Murray, 2005; Noakes, 2009). Zhang (2004 in Sprinkle, 2008) found that since new students are lacking in experience, their reading is affected by the matching of the instructors teaching style with their learning style.

The most important factors that affected the reliability and validity of the students' evaluation of teachers is the fact that most students evaluated teachers according to the grade they have acquired. It was found that students with the lowest GPA were significantly more affected by their grades when rating, and gave higher rates to teachers who gave them better course grades. Most teachers who participated in the study realized this fact. Keane and MacLathrainn (2005) found that students gave teachers who were believed to be easy graders high ratings. Many researchers approved, and believed that this phenomenon was a case of grade inflation, as teachers would give higher grades for students who did not deserve them for the sake of higher evaluation scores.

Mood also affected the rating in the evaluation of teachers. In this study, it was found that younger students were significantly affected by their mood at the time of rating teachers in the evaluation. This finding agrees with Miller (2008) who found in his study that the emotional state of students affected their answers. Miller stated that anxiety, anger, and depression resulted in low evaluation scores even for effective teachers.

\section{Conclusion}

The researchers planned on reviewing the effectiveness of the evaluation form from the perspective of both teachers and students. To do so, they distributed 320 questionnaires to English major students, and 19 questionnaires to the faculty members in the English department. The choice of a particular major might reflect the importance of major - based evaluation forms. Therefore, the questionnaires are only distributed to English major students and the faculty members in the department. Each questionnaire - students' and teachers' - consisted of 20 statements and two open ended questions. The statistics of the answers to the questionnaire statements were calculated in SPSS for frequency, mean, and significance.

Extensive literature was investigated to compare results obtained from the questionnaire with the literature reviewed to identify the views of faculty members and students in the English department in CBE of the current student evaluation of teachers in general, and more specifically, the current evaluation form. Before considering any conclusions, the limitations of the study need to be acknowledged. Obviously, this study was based on one major and one gender. The results would have been more valuable If males were included and other major students as well, that would help interviewing the significant differences between genders, and between majors. Another limitation might be the single instrument of data collection, personal interviews would have been a beneficial instrument added to the questionnaires and the open-ended questions.

In response to the first question in this research, it was found that students did not consider the evaluation to be clear and academically covers all aspects. Most students required open space to write, and wanted to mention office hours and attendance. The majority of students did not feel that online evaluation is important and affected the teachers in anyway.

Faculty members also believe that easy-grading teachers received a better evaluation. Hence, many teachers would give good grades to get higher rating. In addition, the majority of teachers believed that the use of technology should be mentioned in the form, a comment space should be added, and the evaluation should be course-tailored. The lack of an appropriate evaluation form and the lack of the seriousness in filling up the form on the students' side, made only a few teachers care about the outcome. Yet, half the participants worked better to avoid criticism.

In response to the fourth and fifth question of the study, many students agreed that the grades they were given during the course and before the valuation affected the rating of teachers. Some students also admitted that their mood during the filling up of the form affected their assessment greatly. It was found that the younger participants were the most affected by their mood while rating teachers. In addition, students with lower GPA 
were significantly affected more than the others by their grades while rating teachers. Finally, students with the highest GPA felt their importance as students, an important factor in the educational institute, when filling up the evaluation.

The researchers hoped that the study would contribute to the future evaluation of teachers in education generally, and in CBE more specifically by considering a few recommendations. The first and most important recommendation is redesigning the evaluation form to fit the needs of each course and cover all academic areas. To do so, one must add space for comments, add statements about technology and other aspects that have been ignored, and make the statements clearer. Some statements should be tailored for certain courses. Another recommendation might be training students to be able to fulfill their job in evaluating teachers with honesty, away from grade-affect and moodiness. We should also provide students with a better evaluation environment; timing should be considered as well as showing students their importance in the academic structure.

\section{References}

Abrami, P. C., d'Apollonia, S., \& Rosenfield, S. (2007). The dimensionality of student ratings of instruction: What we know and what we do not. In R. P. Perry, \& J. C. Smart (Eds.), The Scholarship of teaching and learning in higher education: An evidence-based perspective (pp. 385-456).

American University of Beirut. (2005). Faculty and student perspectives on student teaching evaluations. Retrieved from http://www.aub.edu.lb /oira/Documents /ic_survey_report.doc

Anderson, M. R., Ingram, J. M., \& Buford, B. J. (2012). Doctoral students' perceptions of perceptions of characteristics of effective college teachers: A mixed analysis. International Journal of Doctoral Studies, 7 , 279-309.

Arbuckle, J., \& Williams, B. D. (2003). Students' perceptions of expressiveness: Age and gender effects on teacher evaluations. Sex Roles, 49, 507-516. http://dx.doi.org/10.1023/A:1025832707002

Basow, S. A., \& Martin, J. L. (2012). Bias in Student Evaluations. In M. E. Kite (Ed.), Effective evaluation of teaching: A guide for faculty and administrators. U.S.: Society for the Teaching of Psychology.

Bavishi, A., Madera, J. M., \& Hebl, M. R. (2010). The effect of professor ethnicity and gender on student evaluations: Judged before met. Journal of Diversity in Higher Education, 3, 245-256.http://dx.doi.org/10.1037/a0020763

Berk, R. A. (2005). Survey of 12 strategies to measure teaching effectiveness. International Journal of Teaching and Learning in Higher Education, 17(1), 48-62.

Beyers, C. (2008). The hermeneutics of student evaluations. College Teaching, 56(2), 102-106. http://dx.doi.org/10.3200/CTCH.56.2.102-106

Biggs, J. (2003). Teaching for quality learning at university (2nd ed.). Buckingham: SRHE/Open University Press.

Brockx, B., Spooren, P., \& Mortelmans, D. (2011). Taking the grading leniency story to the edge: The influence of student, teacher, and course characteristics on student evluations of teaching in higher education. Educational Assessment, Evaluation and Accountability, 23(4), 289-306. http://dx.doi.org/10.1007/s11092-011-9126-2

Brown, M. J. (2008). Student perceptions of teaching evaluations. Journal of Instructional Psychology, 35(2), 177-181.

Burdsal, C. A., \& Harrison, P. D. (2008). Further evidence supporting the validity of both a multidimentional profile and an overall evaluation of teaching effectiveness. Assessment \& Evaluation in Higher Education, 33(5), 567-576. http://dx.doi.org/10.1080/02602930701699049

Canelos, J. (1985). Teaching and course evaluation procedures: A literature review of current research. Journal of Instructional Psychology, 12(4), 187-195

Carr, R., \& Hagel, P. (2008). Students' evaluations of teaching quality and their unit online activity: An empirical investigation. Hello! Where are you in the landscape of educational technology? Proceedings ascilite Melbourne 2008. Retrieved from http://www.ascilite.org.au/conferences/melbourne08/procs/carr-r.pdf

Carrell, S. E., \& West, J. E. (2010). Does professor quality matter? Evidence from assignment of students to professors.Journal of Political Economy, 118(3), 409-432. http://dx.doi.org/10.1080/02602930701699049

Catano, V. M., \& Harvey, S. (2011). Student perception of teaching effectiveness: Development and validation of 
the evaluation of teaching competencies scale. Assessment \& Evaluation in Higher Education, 36(6), 701-717. http://dx.doi.org/10.1080/02602938.2010.484879

Centra, T. A., \& Gaubatz, N. B. (2000). Is there gender bias in student evaluations of teaching? Journal of Higher Education, 71, 17-33.

Danielson, C., \& McGreal, T. L. (2000). Teacher Evaluation to Enhance Professional Practice. Alexandria: Association for Supervision and Curriculum Development.

Davison, E., \& Price, J. (2009). How do we rate? An evaluation of online student evaluations. Assessment \& Evaluation in Higher Education, 34(1), 51-65. http://dx.doi.org/10.1080/02602938.2010.484879

Doyle, T. (2004). Evaluating teacher effectiveness-Research summary. Center for Teaching, Learning and faculty development. Retrieved March 30, 2014, from http://www.learnercenteredteaching.eordpress.com

Feldman, K. (1996). Indentifying exemplary teaching: Using data from course and teacher evaluations: New Directions for Teaching and Learning, 65, 41-50. http://dx.doi.org/10.1080/02602938.2010.484879

Feldman, K. (2007). Identifying exemplary teachers and teaching: Evidence from student ratings. In R. P. Perry, \& J. C. Smart (Eds.), The scholarship of teaching and learning in higher education: An evidence-based perspective (pp. 93-143).

Felton, J., Mitchell, J., \& Stinson, M. (2004). Web-based student evaluation of professors: The relations between perceived quality, easiness \& sexiness. Assessment \& Evaluation in Higher Education, 29(1), 91-108.

Germain, M., \& Scandura, T. (2005). Grade inflation and student individual differences as systematic bias in faculty evaluations. Journal of Instructural Psychology, 32(1), 58-66.

Gordon, P. A. (2001). Student evaluations of college instructors: An overview. As partial requirements for PSY 202: Conditions of Learning. Valdosta State University.

Heine, P., \& Maddox, N. (2009). Student perceptions of the faculty course evaluation process: An exploratory study of gender \& class differences. Research in Higher Education Journal, 3, 1-10.

Hejase, A. J., Alkaakour, R. S., Halawi, L. A., \& Hejase, H. J. (2013). Students' perceptions of student evaluation of teaching (SET) Process. International J. Soc. Sci.\& Education, 3(3),565-575.

Iowa State University. (2011). Student evaluation of teaching: Guidelines and recommendations for effective practice. Retrieved June 11, 2011 from http://dx.doi.org/10.1080/02602938.2010.484879

Iyamu, EOS, \& Adwa J. (2005). Assessment of the Inquiry Teaching Competencies of Social Studies Teachers in Junior Secondary School in EDO State. Benin: University of Benin.

Jacob, B. A., \& Lefgren, L. (2008). Can principals identify effective teachers? Evidence on subjective performance evaluation in education. Journal of Labor Economics, 26(1), 101-136. http://dx.doi.org/10.1086/522974.

Kalayci, N. (2009). The underlying student reasons for rating SET questionnaire items: How student solve the problem of filling out questionnaires. Educational Research Quarterly, 32(4), 36-60.

Keane, E., \& Maclathrainn, I. (2005). Obtaining student feedback on teaching \& course quality. Centre for Excellence in Learning \& Teaching (CELT), April, 1-19.

Kindred, J., \& Mohammed, S. N. (2005). "He will crush you like an academic ninja": An analysis of Ratemyprofessors.com. Journal of Computer Medicated Communication, 10(3). Retrieved March 24, 2014, from http:// jcmc.indiana.edu/vol10/issue3/kindred.html.

Kogan, L. R., Schoenfeld-Tacher, R., \& Hellyer, P. W. (2010). Student evaluations of teaching: Perceptions of faculty based on gender, position, and rank. Teaching in Higher Education, 15(6), 623-636. http://dx.doi.org/10.1080/13562517.2010.491911

Kozub, R. M. (2010). Relationship of course, instructor, and student characteristics to dimensions of student ratings of teaching effectiveness in business schools. American Journal of Business Education, 3(1), 33-40.

Lattuca, L. R., \& Domagal-Goldman, J. M. (2007). Using qualitative methods to assess teaching effectiveness. New directions for institutional research, 136(Winter). http://dx.doi.org/10.1002/ir.233

Lauer, C. (2012). A comparison of faculty and student perspectives on course evaluation terminology. To Improve the Academy, 31, 195-211.

Lekena, L. L., \& Bayaga, A. (2012). Quality assurance in education: Student evaluation of teaching. Int J EduSci, 
4(3), 271-274.

Machingambi, S., \& Newman, W. (2011). University lecturer's perceptions of students evaluation of their instructional practices. Anthropologist, 13(3), 167-174.

McDaniel, J. N. (2008). Student evaluations of instructors: A bad thing? Faculty Focus: Higher ED Teaching Strategies form Magna Publications.

Miller, E. J. (2009). Student evaluations of teaching: Perceived merits and disadvantages and suggestions for improving the assessment method. Paper presented at the Academic and Business Research Institute Conference in Orlando, Fla.

Murray, H. G. (1997). Does evaluation of teaching lead to improvement in teaching? International Journal for Academic Development, 2(1), 8-23. http://dx.doi.org/10.1002/ir.233

Murray, H. G. (2005). Student evaluations of teaching. Has it made a difference? Paper presented at the Annual Meeting of the Society for Teaching and Learning in Higher Education, Charlottetown, Prince Edward Island.

Nasser, F., \& Fresko, B. (2002). Faculty views of student evaluation of college teaching. Assessment \&Evaluation in Higher Education, 27(2), 187-198. http://dx.doi.org/10.1080/02602930220128751

Noakes, L. A. (2009). Adapting the utilization-focused approach for teacher evaluation. Journal of Multi Disciplinary Evaluation, 6(11), 83-88.

Olatoye, R. A., \& Aanu, E. M. (2011).Senior secondary school science teachers' perception of using student to evaluate teaching effectiveness. Journal of Emerging Trends in Educational Research \& Policy Studies (JETERAPS), 2(3), 164-170.

Patrick, M. J. (1997). Valuing the individual student: Using single subject design as a tool for evaluating classroom teaching performance. Journal of Social Work Education, 33(2), 261-274.

Penny, A. R. (2003). Changing the agenda for research into students' views about university teaching: Four shortcomings of SRT research. Teaching in Higher Education, 8(3), 399-411. http://dx.doi.org/10.1080/13562510309396

Riniolo, T. D., Johnson, K. C., Sherman, T. R., \& Misso, J. A. (2006). Hot or not: Do professors perceived as physically attractive receive higher student evaluations? Journal of General Psychology, 133, 19-35. http://dx.doi.org/10.3200/GENP.133.1.19-35

Roxa, T., Anderson, R., \& Warfringe, P. (2007). Making use of student evaluations of teaching in a "culture of quality". Paper presented to the $29^{\text {th }}$ Annual Eair Forum 26 to 29 August 2007. Innsbruck, Austria.

Sheppard, J. D. (2013). Perceptions of teachers and administrators regarding the teacher evaluation process. PhD Thesis. Georgia Southern University.

Silva, K. M., Silva, F. J., Quinn, M. A., Draper, J. N., Cover, K. R., \& Munoff, A. A. (2008). Rate my professor: Online evaluations of psychology instructors. Teaching of Psychology, 35(2), 71-80. http://dx.doi.org/10.1080/00986280801978434

Spiller, D., \& Harris, T. (2013). Learning from evaluations: Probing the reality. Issues in Educational Research, 23(2), 258-268.

Spooren, P., Mortelmans, D., \& Denekens, J. (2007). Student evaluation of teaching quality in higher education: development of an instrument based on 10 Likert-scales. Assessment \& Evaluation in Higher Education, 32(6), 667-679. http://dx.doi.org/10.1080/02602930601117191

Sprinkle, J. E. (2008). Student perceptions of effectiveness: An examination of the influence of student biases. College Student Journal, 42(2), 276-293.

Surratt, C. K., \& Desselle, S. P. (2007). Pharmacy students' perceptions of a teaching evaluation process. American Journal of Pharmaceutical education, 71(1), 1-7. http://dx.doi.org/10.5688/aj710106

Thomas, E., \& Wingert, P. (2010). Why we must fire bad teachers. Newsweek. Retrieved from http://www.newsweek.com/2010/03/05/why -we -must -fire -bad-teachers.html

Thornton, B., Adams, M., \& Sepehri, M. (2010). The impact of students' expectations of grades and perceptions of course difficulty, workload, and pace on faculty evaluations. Contemporary Issues in Education Research, $3(12), 1-6$. 
Turpen, C., Henderson, C., \& Dancy, M. (2012). Faculty perspectives about instructor and institutional assessments of teaching effectiveness. A paper presented at the physics Education Research Conference AIP Conf. Proc. 1413, 371-374.

Weimer, M. (2012). End-of-course evaluations: Making sense of student comments. Faculty focus: Higher ED Teaching Strategies from Magna Publications. The Teaching Professor BLOG.

Weinberg, B. A., Fleisher, M., \& Hashimoto, M. (2007). Evaluating methods for evaluating instruction: The case of higher education. NBER Working paper No. 12844 issued in Jan. 2007.

Weinberg, B. A., Hashimoto, M., \& Fleisher, B. (2009). Evaluating teaching in higher education. Journal of Economic Education, 40(3), 227-261. http://dx.doi.org/10.3200/JECE.40.3.227-261

Wines, W. A. (2006). Observations on the folly of using student evaluations of college teaching for faculty evaluation, pay, and retention decisions and its implications for academic freedom. William \& Mary Journal of Women and the Law, 13(1), 167-202.

Wright, R. (2006). Student evaluations of faculty concerns raised in the literature and possible solutions. College Student Journal, 40(2), 417-422.

Zhang, L. F. (2004). Thinking styles: University students' preferred teaching styles and their conceptions of effective teachers. The Journal of Psychology, 138(3), 233-252. http://dx.doi.org/10.3200/JRLP.138.3.233-252

\section{Appendix A}

Division of statements in the students' questionnaire

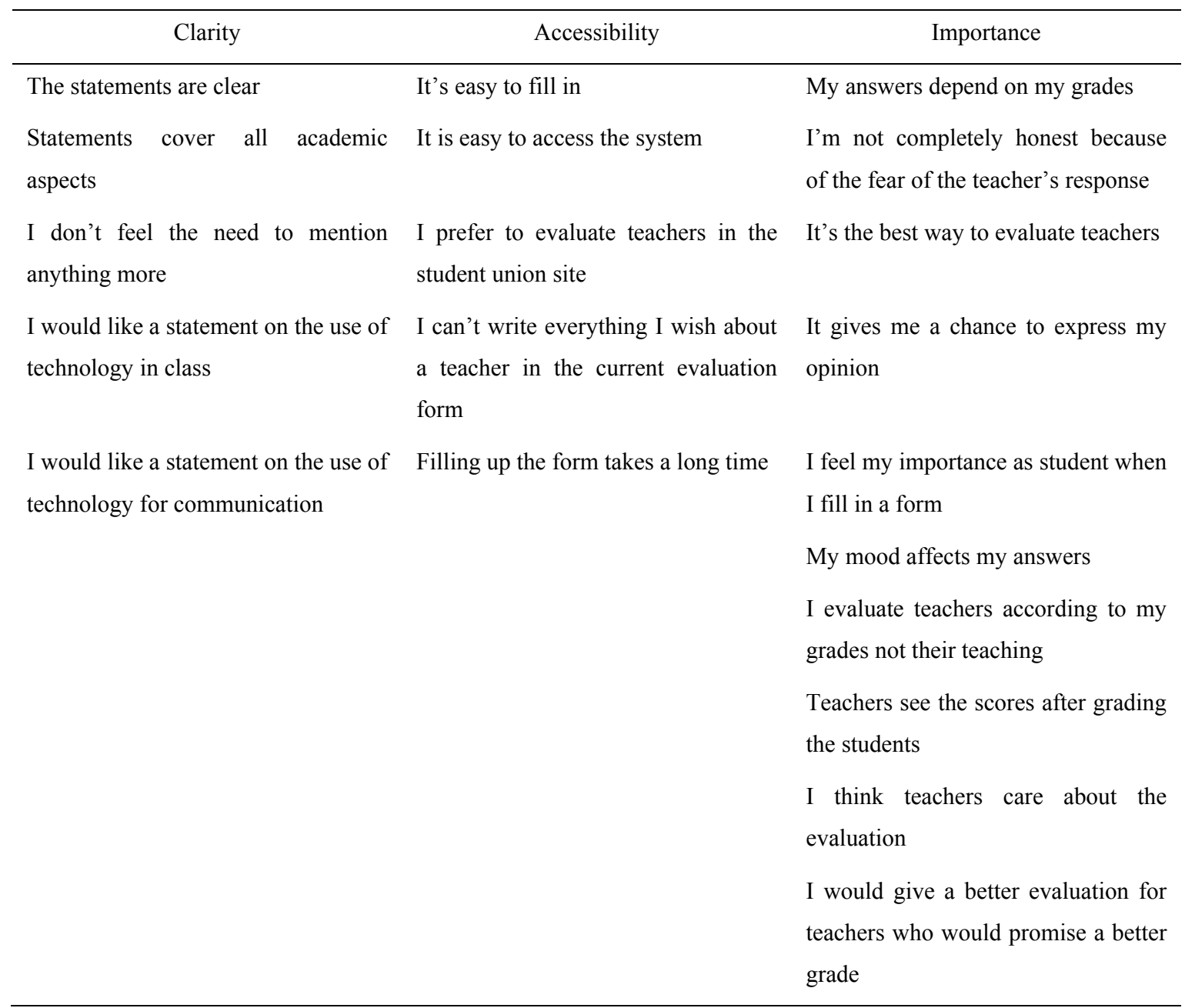




\section{Division of statements in the teachers' questionnaire}

\begin{tabular}{|c|c|c|}
\hline Clarity & Accessibility & Importance \\
\hline The statements are clear & It's easy to follow up & $\begin{array}{l}\text { It's an important way to evaluate } \\
\text { teachers }\end{array}$ \\
\hline $\begin{array}{l}\text { Statements cover all academic } \\
\text { aspects }\end{array}$ & $\begin{array}{l}\text { Students are competent and can fill } \\
\text { in an evaluation wisely }\end{array}$ & It's the best way to evaluate teachers \\
\hline $\begin{array}{l}\text { I would like a statement on the use of } \\
\text { technology in class }\end{array}$ & It's very discrete & $\begin{array}{l}\text { It gives me an opportunity to learn } \\
\text { from the students' answers }\end{array}$ \\
\hline $\begin{array}{l}\text { I would like a statement on the use of } \\
\text { technology for communication }\end{array}$ & $\begin{array}{l}\text { Many students don't evaluate their } \\
\text { teachers }\end{array}$ & $\begin{array}{l}\text { I think the evaluation includes } \\
\text { suggestions for me to improve my } \\
\text { teaching }\end{array}$ \\
\hline \multirow[t]{7}{*}{ The evaluation criteria is clear } & & $\begin{array}{l}\text { Students expect good grades when } \\
\text { filling in the forms }\end{array}$ \\
\hline & & $\begin{array}{l}\text { Teachers provide less teaching } \\
\text { material to get a better evaluation }\end{array}$ \\
\hline & & $\begin{array}{l}\text { Students evaluate me according to } \\
\text { their grades }\end{array}$ \\
\hline & & $\begin{array}{l}\text { Students evaluation scores depends } \\
\text { mainly on their mood at the time of } \\
\text { evaluating }\end{array}$ \\
\hline & & I care about the evaluation outcome \\
\hline & & $\begin{array}{l}\text { Teachers provide a better grade to } \\
\text { get a better evaluation }\end{array}$ \\
\hline & & $\begin{array}{l}\text { "Emotions" are the key to students' } \\
\text { evaluation }\end{array}$ \\
\hline
\end{tabular}

\section{Copyrights}

Copyright for this article is retained by the author(s), with first publication rights granted to the journal.

This is an open-access article distributed under the terms and conditions of the Creative Commons Attribution license (http://creativecommons.org/licenses/by/3.0/). 